\title{
Audit of Postoperative Surgical Intensive Care Unit Admissions
}

\author{
Shaili K. Patel, Samir M. Kacheriwala, Dipesh D. Duttaroy \\ Department of Surgery, Medical College Baroda, Sir Sayajirao General Hospital, Vadodara, Gujarat, India
}

\section{Abstract}

Objective: The objective of this study was to conduct an audit of Surgical Intensive Care Unit (SICU) for identifying the admission risk factors and evaluating the outcomes of postoperative surgical patients. Design: This was a prospective, observational study. Setting: This study was conducted at SICU of a 1500-bedded tertiary care university hospital in Western India. Subject and Methods: Two hundred and forty patients admitted to the SICU postoperatively over a period of 15 months. Results: Planned and unplanned postoperative SICU admission rate was $4.45 \%$ and $0.09 \%$ of the 5284 patients operated. Indications for planned admissions included preoperative medical illnesses, anticipated blood loss, and anticipated mechanical ventilation while unpredicted intraoperative hypotension was the principal cause of unplanned admittance. Univariate analysis for two groups of the American Society of Anesthesiologists (ASA) physical status indicated that advanced age, high American College of Cardiology/American Heart Association (ACC/AHA) surgical risk, emergency surgery, planned admissions, and mortality were related to high ASA class. Analysis for ACC/AHA surgical risk showed association of high ACC/AHA surgical risk with advanced age, male gender, high ASA physical status, emergency surgery, planned admissions, and mortality. High mortality was observed in patients with SICU stay of $>7$ days (75.86\%) and readmitted cases (72.73\%). Conclusion: The need for postoperative critical care is significantly higher in males, elderly, patients with poor preoperative risk stratification scores, preexisting medical illness, major intraoperative hemorrhage, hypotension requiring inotropic support, perioperative respiratory problems and patients undergoing abdominal, trauma, and emergent surgeries. A larger study inclusive of other surgical subspecialties would aid in optimal decision-making for admissions to the SICU.

Keywords: Mortality, postoperative admissions, surgical audit, Surgical Intensive Care Unit

\section{INTRODUCTION}

Medical audit is the "methodical, critical study of the quality of healthcare, the procedures used for patient management, the use of resources, and the resulting outcome and quality of human life." $[1]$ Medical research related to the assessment of perioperative risk factors and it's correlation with the Surgical Intensive Care Unit (SICU) outcomes is limited; hence, an audit would potentially reveal additional new information, contribute to improve intensive-care outcomes, and resource utilization, thereby reducing the economic burden on the patient and hospital.

Over $40 \%$ of SICU admissions are postoperative. ${ }^{[2-4]}$ Postoperative intensive care is necessitated by anticipated or unpredicted complications related to anesthesia, surgery, or underlying illnesses unmasked during surgery. The complex interaction between the surgery performed, preexisting comorbidities and perioperative events determine the postoperative outcomes. ${ }^{[5]}$ Early identification of indicators predicting postoperative adverse events, such as longer

\begin{tabular}{|l|l|}
\hline \multicolumn{3}{c|}{ Access this article online } \\
\hline Quick Response Code: & Website: \\
& www.ijccm.org \\
\hline
\end{tabular}

hospital stay, disability, and death, would prevent unfavorable consequences. $^{[6,7]}$ The present audit was conducted to recognize the causes of postoperative SICU admissions, to identify accountable peri-operative factors, and to determine the outcomes in terms of mortality, morbidity, SICU stay, and discharge.

\section{Subject and Methods}

\section{Patient and settings}

A prospective, observational study was conducted at a 1500-bedded tertiary care Government University Hospital in Western India during the period October 2014 to January 2016, after obtaining prior approval of the Institutional Ethics Committee. Out of the 257 postoperative patients

\section{Address for correspondence: Dr. Dipesh D. Duttaroy, Department of Surgery, Medical College Baroda, Sir Sayajirao General Hospital, Vadodara - 390 001, Gujarat, India. E-mail: drduttaroy@gmail.com}

This is an open access article distributed under the terms of the Creative Commons Attribution-NonCommercial-ShareAlike 3.0 License, which allows others to remix, tweak, and build upon the work non-commercially, as long as the author is credited and the new creations are licensed under the identical terms.

For reprints contact: reprints@medknow.com

How to cite this article: Patel SK, Kacheriwala SM, Duttaroy DD. Audit of postoperative surgical intensive care unit admissions. Indian J Crit Care Med 2018;22:10-5. 
admitted to the SICU 240 were evaluated, 17 patients were excluded due to incomplete data. Patients with at least one overnight stay in the SICU after surgery and postoperative patients readmitted within 7 days of transfer from the SICU were included in this study. Patients transferred to general ward immediately after surgery, presurgical SICU admissions, and readmissions after 7 days of transfer to the ward were excluded from the study.

\section{Variables}

Preoperative variables affecting patient health such as age, gender, and other clinical data including the American Society of Anesthesiologists (ASA) physical status, the American College of Cardiology/American Heart Association (ACC/ AHA) surgical risk, Simplified Revised Cardiac Index (SRCI), Injury Severity Score (ISS), and Glasgow Coma Scale (GCS) were recorded. Patients were grouped for age ( $\leq 40$ and $>40$ years); ASA class $\leq 3$ or $>3$; AHA/ACC high, intermediate, or low risk; 0 or 1 predictor of SRCI; ISS scale $\leq 25$ or $>25$; and $\leq 8$ or $>8$ GCS scale.

Operative variables assessed were the surgical procedure, emergent, or elective schedule and type of anesthesia. Duration of the surgery and anesthetic period were documented as $\leq 4$ and $>4$ h.

Postoperative variables evaluated were the planned/unplanned nature of admission and surgical outcomes. Planned admissions included patients in whom preoperative decision of admission was made based on ASA class, ACC/AHA surgical risk, SRCI, preoperative medical illness, and anticipated major blood loss/prolonged duration of surgery or anesthesia/ mechanical ventilation and airway problems. Unplanned admissions were not foreseen preoperatively but made due to intraoperative respiratory problems, persistent tachycardia, and unexpected major blood loss or hypotension requiring perioperative inotropic support. Morbidity outcome assessment was indicated by the length of SICU stay, SICU mortality, and 30-day-mortality.

\section{Statistical tests and statistical analysis}

Data were analyzed using SPSS software version 23 (SPSS. Armonk, NY: IBM Corp: 2015). Mean and standard deviation for continuous data and number and percentage for categorical variables were calculated. Nonparametric ANOVA test was used for continuous and ordinal variables, considering skewed distribution. Pearson's Chi Square test or Fisher's exact test was used for categorical data. All tests were two-tailed with $P<0.05$ considered statistically significant. Univariate analysis was done for ASA physical status and ACC/AHA surgical risk to check for their association with the outcomes. Results of these analyses were used in regression analysis. Negative binomial regression was performed for count outcome that was over-dispersed, such as the length of SICU stay. Logistic regression was used for dichotomous outcome like mortality. Goodness of fit Chi-square test and Hosmer and Lemeshow test were applied as measures of fitness for the regression models. Odds ratio for mortality was calculated for age, gender, ASA physical status, GCS, ISS, nature and type of surgery, duration of surgery and anesthesia, nature of SICU admission (planned/unplanned), indication for SICU admission, readmission, and length of SICU stay.

\section{RESULTS}

SICU admission rate for postoperative patients was $4.54 \%$. Of the 5284 surgeries performed, the rates for planned and unplanned admissions were $4.45 \%$ and $0.09 \%$, respectively. Patient characteristics, observed parameters, and their odds ratio for mortality are described in Table 1 . There were $75.42 \%$ patients belonging to ASA Class IV. Majority of trauma patients had severe head injury, and 58.93\% had ISS between 26 and 50. Fatality was more in patients with higher ASA class and lower GCS scale [Table 1]. Among the patients admitted, 182 had undergone nontraumatic abdominal surgery, 39 trauma surgery, 16 emergent neurosurgery, and three debridement. Three surgeries were performed under regional anesthesia, two under local, and the rest under general anesthesia. As the three groups had wide variation in numbers, analysis did not illustrate any correlation with mortality. Duration of surgery was $<2 \mathrm{~h}$ in $30 \%$ between 2 and 4 in $61.25 \%$, four to six in $6.25 \%$, and $>6 \mathrm{~h}$ in $2.50 \%$ patients. Surgeries entailing anesthesia for a period of $2-4 \mathrm{~h}$ were $61.60 \%$, while the anesthesia period was $<2 \mathrm{~h}$ in $27.85 \%$, four to six in $8.02 \%$, and $>6 \mathrm{~h}$ in $2.53 \%$. Three procedures performed under regional anesthesia could not be evaluated for the duration. Patients undergoing neurosurgical procedure had the highest risk of death (odds ratio $=4.4$ ). No significant association could be found between the duration of surgery, duration of anesthesia, and mortality. Preoperative medical illnesses anticipated blood loss and anticipated mechanical ventilation were responsible for the majority of planned admissions while unexpected intraoperative hypotension was the principal cause of unplanned admittance [Table 2]. Emergency surgeries and planned admissions were predisposed to unfavorable outcomes [Table 1]. Respiratory complications were observed in $11.25 \%$, cardiac in $16.25 \%$, neurological in $3.33 \%$, and a combination of two or more of the above problems in $18.75 \%$ patients. Almost 50\% patients without any obvious systemic complications were admitted for postoperative monitoring after major surgery. The odds of mortality were most when two or more organ systems were involved (odds ratio $=6.67$ ).

Patients with prolonged SICU stay were at a greater risk of death [Table 1]. The mortality in patients with a SICU admission more than a week was $75.86 \%$ compared to $33.18 \%$ in a shorter stay. Subanalysis for the length of ICU stays indicated that patients aged $>40$ years, ASA scale $>3$, ISS score $>25$, emergent surgeries, multiple system dysfunctions, and readmitted patients had higher risk of stay of $>7$ days. The probability of shorter SICU stay was more in younger patients, better ASA physical status, lower ISS scores, elective surgeries, single system failure, and nonreadmitted patients [Table 3]. Probability for longer or shorter stay for gender and GCS could not be identified [Table 3]. Of the 22 readmitted 


\begin{tabular}{|c|c|c|c|c|}
\hline Variable & $\begin{array}{c}\text { Mean } \pm \text { SD } \\
\text { or }(\%)\end{array}$ & $n$ & OR for mortality & $P$ \\
\hline \multicolumn{5}{|l|}{ Age (years) } \\
\hline$\leq 40$ & $43.73 \pm 16.58$ & 108 & 1 & 0.062 \\
\hline$>40$ & & 132 & $1.706(1.002-2.904)$ & \\
\hline \multicolumn{5}{|l|}{ Gender } \\
\hline Female & 25.42 & 61 & 1 & 1.000 \\
\hline Male & 74.58 & 179 & $1.036(0.569-1.886)$ & \\
\hline \multicolumn{5}{|l|}{ ASA } \\
\hline$\leq 3$ & 9.58 & 23 & 1 & 0.012 \\
\hline$>3$ & 90.42 & 217 & $4.635(1.337-16.071)$ & \\
\hline \multicolumn{5}{|l|}{ ACC/AHA } \\
\hline High & 92.08 & 221 & - & \\
\hline $\begin{array}{l}\text { Intermediate } \\
+ \text { low }\end{array}$ & 7.92 & 19 & - & \\
\hline \multicolumn{5}{|l|}{ SRCI } \\
\hline 0 predictor & 97.14 & 34 & - & \\
\hline 1 predictor & 2.86 & 1 & - & \\
\hline \multicolumn{5}{|l|}{ GCS } \\
\hline$>8$ & 47.83 & 11 & 1 & 0.021 \\
\hline$\leq 8$ & 52.17 & 12 & $8.750(1.241-61.683)$ & \\
\hline \multicolumn{5}{|l|}{ ISS } \\
\hline$\leq 25$ & 25 & 14 & 1 & 0.877 \\
\hline$>25$ & 75 & 42 & $0.909(0.271-3.049)$ & \\
\hline \multicolumn{5}{|l|}{$\begin{array}{l}\text { Nature of } \\
\text { surgery }\end{array}$} \\
\hline Elective & 14.17 & 34 & 1 & 0.007 \\
\hline Emergency & 85.83 & 206 & $3.344(1.327-8.427)$ & \\
\hline \multicolumn{5}{|l|}{$\begin{array}{l}\text { Duration of } \\
\text { surgery }(\mathrm{h})\end{array}$} \\
\hline$\leq 4$ & 91.25 & 219 & 1 & 0.622 \\
\hline$>4$ & 8.75 & 21 & $0.788(0.306-2.032)$ & \\
\hline \multicolumn{5}{|l|}{$\begin{array}{l}\text { Duration of } \\
\text { anesthesia (h) }\end{array}$} \\
\hline$\leq 4$ & 89.45 & 212 & 1 & 0.800 \\
\hline$>4$ & 10.55 & 25 & $0.910(0.384-2.155)$ & \\
\hline \multicolumn{5}{|l|}{$\begin{array}{l}\text { Nature of } \\
\text { admission }\end{array}$} \\
\hline Unplanned & 2.08 & 5 & 1 & 0.394 \\
\hline Planned & 97.92 & 235 & $2.528(0.278-22.973)$ & \\
\hline \multicolumn{5}{|l|}{$\begin{array}{l}\text { Length } \\
\text { of SICU } \\
\text { stay (days) }\end{array}$} \\
\hline$\leq 7$ & $3.45 \pm 3.30$ & 211 & 1 & $<0.001$ \\
\hline$>7$ & & 29 & $6.331(2.580-15.532)$ & \\
\hline \multicolumn{5}{|l|}{$\begin{array}{l}\text { Readmission } \\
\text { to the SICU }\end{array}$} \\
\hline No & 90.83 & 218 & 1 & $<0.001$ \\
\hline Yes & 9.17 & 22 & $4.982(1.872-13.259)$ & \\
\hline \multicolumn{5}{|c|}{$\begin{array}{l}\text { SD: Standard deviation; OR: Odds ratio; ASA: American Society } \\
\text { of Anesthesiologists; ACC: American College of Cardiology; } \\
\text { AHA: American Heart Association; SRCI: Simplified Revised Cardiac } \\
\text { Index; SICU: Surgical Intensive Care Unit; GCS: Glasgow Coma Scale; } \\
\text { ISS: Injury Severity Score }\end{array}$} \\
\hline
\end{tabular}

patients, 16 expired in the ICU and 2 within the 30 -day period. In-hospital mortality rate was $38.33 \%$ while the SICU mortality

\begin{tabular}{|c|c|c|c|}
\hline & \multicolumn{3}{|c|}{ Mortality } \\
\hline & Yes, $n(\%)$ & No, $n(\%)$ & Total, $n$ \\
\hline \multicolumn{4}{|l|}{$\begin{array}{l}\text { Indications for planned } \\
\text { admission to SICU }\end{array}$} \\
\hline SRCI & 0 & $1(100)$ & 1 \\
\hline Preoperative medical illness & $72(41.38)$ & $102(58.62)$ & 174 \\
\hline Duration of surgery & $2(22.22)$ & $7(77.78)$ & 9 \\
\hline Duration of anesthesia & $2(22.22)$ & $7(77.78)$ & 9 \\
\hline Anticipated blood loss & $89(38.86)$ & $140(61.14)$ & 229 \\
\hline $\begin{array}{l}\text { Anticipated mechanical } \\
\text { ventilation }\end{array}$ & $89(38.53)$ & $142(61.47)$ & 231 \\
\hline Anticipated airway problems & $2(100)$ & 0 & 2 \\
\hline \multicolumn{4}{|l|}{$\begin{array}{l}\text { Indications for unplanned } \\
\text { admission to SICU }\end{array}$} \\
\hline $\begin{array}{l}\text { Intraoperative respiratory } \\
\text { problems }\end{array}$ & 0 & $1(100)$ & 1 \\
\hline Unanticipated hypotension & $1(33.33)$ & $2(66.67)$ & 3 \\
\hline Major blood loss & 0 & $1(100)$ & 1 \\
\hline
\end{tabular}

rate was $36.67 \%$. Four out of 92 patients died in ward after being transferred. Of the 148 discharged patients, $8.75 \%$ died during the 30-day follow-up period.

\section{Peri-operative risk factors determining Surgical Intensive Care Unit outcomes}

On univariate analysis for ASA physical status, a significant difference was found between the two groups for age, ACC/AHA surgical risk, emergency surgery, planned admission, and mortality while gender, SRCI, readmission, length of SICU stay, and 30-day mortality were unrelated. There was a statistically significant difference between the two groups of ACC/AHA surgical risk with relation to age, gender, ASA physical status, emergency surgery, type of admission, and mortality [Table 4]. Other variables such as SRCI, ISS, GCS, nature of surgery, and type of admission did not show any correlation with the outcomes. Multivariate regression analysis adjusting for confounding factors demonstrated a positive correlation between SICU length of stay and ACC/AHA risk stratification model and SICU length of stay and mortality. Inverse association was observed between preoperative high ACC/AHA surgical risk and mortality [Table 5].

\section{Discussion}

The higher rate of SICU admissions for operated patients in this audit correlates with the poor preoperative physical status as evident from the risk assessment scales studied such as ASA physical status, ACC/AHA surgical risk, GCS, and ISS.[2,4,8] The study shows a lower rate of unplanned admissions $(0.09 \%)$ than that reported in other audits. ${ }^{[2,9,10]}$ This might have been either due to better preoperative evaluation and optimum intraoperative care resulting in less postoperative serious adverse events or to the methodology of data collection. 


\section{Table 3: Risk factors for shorter Surgical Intensive Care Unit stay}

\begin{tabular}{|c|c|c|c|c|}
\hline & \multirow[t]{2}{*}{ Risk factors } & \multirow[t]{2}{*}{ OR for probability of shorter stay } & \multicolumn{2}{|c|}{$95 \% \mathrm{Cl}$} \\
\hline & & & Lower & Upper \\
\hline \multirow[t]{8}{*}{ SICU length of stay ( $\leq 7$ days $/>7$ days) } & Age $(\leq 40$ years $/>40$ years $)$ & 1.392 & 0.627 & 3.090 \\
\hline & Sex (female/male) & 1.108 & 0.449 & 2.737 \\
\hline & $\operatorname{ASA}(\leq 3 />3)$ & 1.492 & 0.331 & 6.723 \\
\hline & $\operatorname{GCS}(>8 / \leq 8)$ & 0.900 & 0.104 & 7.781 \\
\hline & ISS $(\leq 25 />25)$ & 1.200 & 0.218 & 6.587 \\
\hline & Emergency (no/yes) & 1.493 & 0.426 & 5.233 \\
\hline & Multiple organ failure (no/yes) & 1.448 & 0.572 & 3.635 \\
\hline & Readmission (no/yes) & 2.377 & 0.804 & 7.026 \\
\hline
\end{tabular}

SICU: Surgical Intensive Care Unit; OR: Odds ratio; CI: Confidence interval; ASA: American Society of Anesthesiologists; GCS: Glasgow Coma Scale; ISS: Injury Severity Score

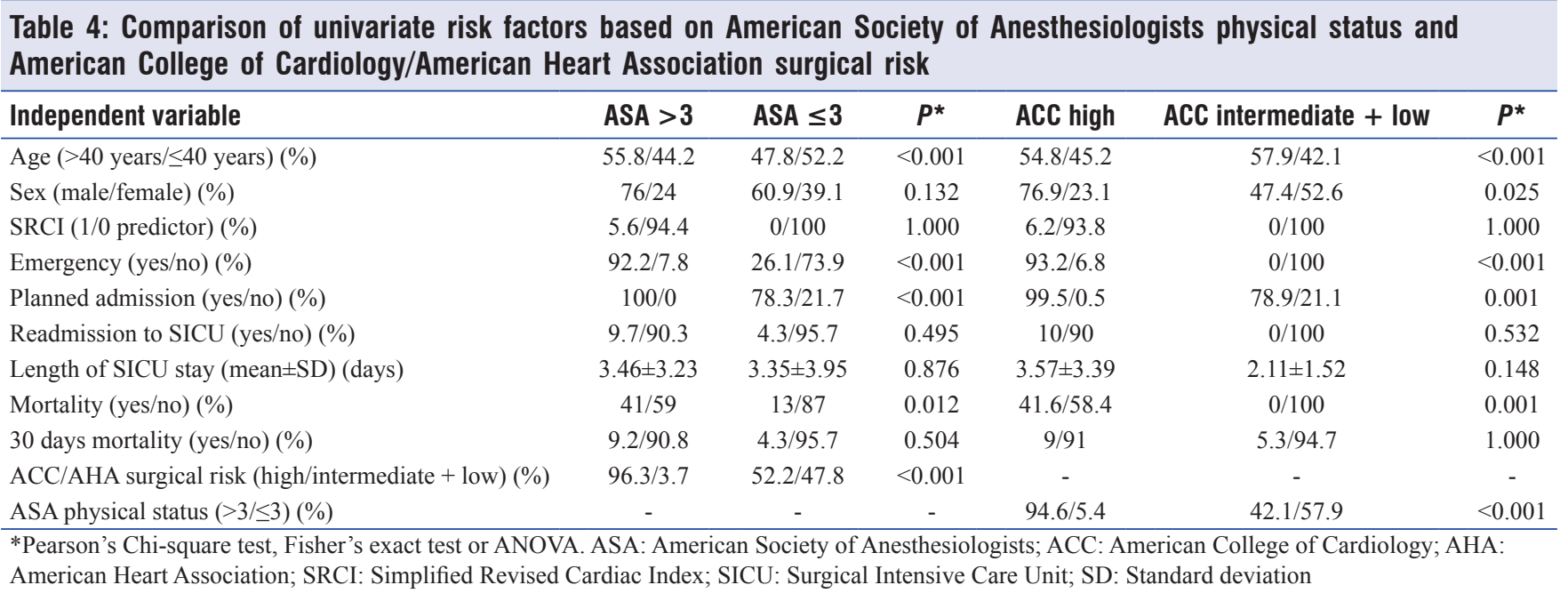

\section{Table 5: Multivariate regression analysis: Odds ratio}

\begin{tabular}{|c|c|c|c|c|}
\hline \multirow{2}{*}{$\begin{array}{l}\text { Outcome } \\
\text { variables }\end{array}$} & \multirow[t]{2}{*}{ Independent variables } & \multirow[t]{2}{*}{ OR } & \multicolumn{2}{|c|}{$95 \% \mathrm{CI}$} \\
\hline & & & Lower & Upper \\
\hline \multirow{5}{*}{$\begin{array}{l}\text { SICU length } \\
\text { of stay }^{\mathrm{a}}\end{array}$} & Age ( $>40$ years $/ \leq 40$ years) & 1.137 & 0.847 & 1.528 \\
\hline & Sex (male/female) & 0.923 & 0.656 & 1.300 \\
\hline & $\operatorname{ASA}(>3 / \leq 3)$ & 0.846 & 0.485 & 1.474 \\
\hline & $\begin{array}{l}\text { ACC/AHA risk (high/ } \\
\text { intermediate }+ \text { low) }\end{array}$ & 1.475 & 0.741 & 2.937 \\
\hline & Mortality (yes/no) & 1.414 & 1.041 & 1.920 \\
\hline \multirow[t]{4}{*}{ Mortality ${ }^{b}$} & Age ( $>40$ years $/ \leq 40$ years) & 0.563 & 0.325 & 0.974 \\
\hline & Sex (male/female) & 1.196 & 0.631 & 2.267 \\
\hline & $\operatorname{ASA}(>3 / \leq 3)$ & 0.453 & 0.118 & 1.743 \\
\hline & $\begin{array}{l}\text { ACC/AHA risk (intermediate } \\
+ \text { low/high) }\end{array}$ & 1.391 & - & - \\
\hline
\end{tabular}

\section{Demographic profile and its relation to Surgical Intensive Care Unit outcomes}

Higher admission rates were observed for males and elderly alike one previous study. ${ }^{[2]}$ The risk of death was 1.7 times higher in patients $>40$ years which reiterate the findings that debilitating morbidity and mortality occur more frequently in elderly. ${ }^{[1,12]}$ Male preponderance could be explained by their predisposition to cardio-pulmonary diseases, exclusion of gynecological surgeries from the study, and inclusion of trauma patients. The elderly besides suffering from illness such as hypertension and diabetes have poor physiological reserves to deal with postoperative complications.

\section{Risk stratification models and their association with outcomes}

ASA physical status has a questionable consistency in predicting the true morbidity and mortality of a patient based on his physical condition before surgery. Here, it has showed an association with mortality [Table 1] but could not predict the impact on the SICU length of stay, which was highlighted in some earlier reports. ${ }^{[13,14]}$ Lupei et al. observed better results, in terms of readmission to SICU and mortality, since $81 \%$ of their patients fell under the intermediate risk group when surgically graded according to ACC/AHA guidelines. ${ }^{[14]}$ SRCI could not be labeled a reliable prognosticator of intensive care since most of our patients had zero predictors, which correlate with $<1 \%$ cardiac complications. ${ }^{[15]}$

Mortality in postoperative trauma patients was higher $(38.46 \%)$ than that noted in a Tanzanian study (32.7\%), which included 
both operated and conservatively treated patients. ${ }^{[16]}$ Surgery adds to the risk of mortality, probably the reason behind higher mortality here. Postoperative patients with GCS $<8$ had higher risk of mortality in concurrence with the finding that fatality is higher for patients with severe head injury and high ISS. ${ }^{[16]}$

\section{Operative variables and their role in determining Surgical Intensive Care Unit outcomes}

Emergent acute abdominal surgeries provide little time for the optimization of vital parameters and preoperative evaluation of patients, which increases the risk of postoperative complications, and this may explain the high-mortality rate $(70.65 \%)$ recorded for emergency surgeries in the current audit. ${ }^{[8,12,13]}$ No correlation could be construed from this audit explaining the relation between anesthetic time and intra-and post-operative complication rate contrasting with a previous report, stating that longer duration of anesthesia and surgery allows greater time for physiological trespass and hence a greater risk for complications. ${ }^{[17]}$

The large proportion of planned admissions in this study could have been a result of overzealous identification of emergency surgeries as high-risk procedures. We failed to evaluate a comparable group of patients not requiring intensive care and hence failed to assess the validity of planned admissions. Despite numerous publications reporting cardiovascular and respiratory complications as main reasons for unplanned admissions, we could not conclude the same due to a very small number of unplanned admissions..$^{[2,4,10]}$ Reasons for SICU admissions, both planned and unplanned, indicate the organ dysfunction that might have occurred during the peri-operative period. Unplanned admissions represent unanticipated surgical or anesthetic intraoperative complications and failure to recognize such adverse events early could contribute to a poor outcome.

\section{Postoperative variables and their relation with Surgical Intensive Care Unit outcomes}

More than $50 \%(n=122)$ of the patients admitted to the SICU had septic shock, acute renal failure, or unidentified but serious indications that required ICU care. Overall survival was lower $(29.55 \%)$ in patients with multiple organ failure. Premature discharge of patients from the SICU due to shortage of beds probably resulted in a high readmission rate $(9.16 \%)$ than that noted by Lupei et al. (5\%). ${ }^{[14]} \mathrm{A}$ similar or higher readmission rate was observed in two other observational studies. ${ }^{[18,19]}$ Kaben et al., who analyzed both operated and conservatively managed patients attributed the higher readmission rate $(13.4 \%)$ to patients with older age, organ failure, sepsis syndrome, and poor preoperative status. ${ }^{[19]}$ Mortality in readmitted (72.73\%) and nonreadmitted (36.86\%) patients was much higher compared to the $17.1 \%$ and $2.9 \%$ observed by Kaben et al.; this may have been because our study population comprised of only postoperative patients. ${ }^{[19]}$

\section{Outcomes}

Prior audits have recognized the direct impact of severe illness and preoperative medical conditions on the length of
SICU stay. ${ }^{[6,13]}$ Very short duration of stay suggests improper selection of patients for the SICU with overestimation of planned admissions and more number of unnecessary admissions. Young patients with better risk assessment scores, patients undergoing elective surgeries or single system dysfunction and nonreadmitted patients were more likely to have a shorter duration of stay. These low-risk groups may not require intensive care and step down units or intermediate care units can be a solution to this problem. A length of SICU stay $>7$ days has been strong predictor of adverse postoperative consequences, and the findings of high fatality in patients staying for $>7$ days in the SICU in the current audit were in accordance with the findings of a previous observational study. ${ }^{[13]}$ Similar to Abelha et al., ${ }^{[13]}$ we identified certain risk factors for prolonged SICU stay and all of them showed independent correlation with mortality. Such indicators of poor health support the assumption that more severely ill patients require longer duration of treatment in the ICU. A large proportion of ICU resources are spent on long stay group; hence, it is prudent to recognize factors contributing to short or long SICU stay, which can assist in classifying patients into low and high-risk categories respectively. This would prevent unwanted resource-depleting SICU admissions in developing nations. The 30-day-mortality observed by Lupei et al. was $3.2 \%$ compared to $8.75 \%$ noted by us and this may be explained by the fewer ( $32 \%$ vs. $85.83 \%$ ) high-risk emergency surgeries studied by them. ${ }^{[14]}$

\section{Univariate and multivariate analysis}

Univariate analysis for two groups of ASA physical status indicated that increased age, high ACC/AHA surgical risk, emergency surgery, planned admission, and mortality were related to high ASA physical status. Analysis for ACC/AHA surgical risk showed association of high ACC/AHA surgical risk with increased age, male gender, high ASA physical status, emergency surgery, planned admission, and mortality. A similar study had failed to identify any association between ASA class and demographic factors or nature of surgery; however, it could highlight the significance of ACC/AHA surgical risk in predicting SICU outcomes. ${ }^{[14]}$

Findings of multivariate regression analysis were consistent with two other studies suggesting that patients with prolonged SICU stay had higher ACC/AHA surgical risk before surgery and poor survival. ${ }^{[13,14]}$ Contradictory to the findings of Lupei et al., it was observed that low and intermediate ACC/AHA surgical risk groups had high mortality, possibly because of wide variation in the sample size of two groups of ACC/AHA surgical risk. ${ }^{[14]}$

\section{Strengths and limitations of the study}

Multiple risk stratification models were studied in this audit, unlike other studies, to check for their association with the SICU eventuality. Sample size in spite of being relatively small was adequately powered to show correlation between perioperative variables and SICU outcomes. The number of cases with one predictor of SRCI and unplanned admissions 
being less, we could not reliably assess their relation with outcomes. Plastic surgery, elective neurosurgical, obstetric and gynecological, otorhinolaryngological, orthopedic, urological, vascular, and ophthalmological procedures were not evaluated. A majority of the postoperative pediatric patients $(<5$ years) were shifted to pediatric ICU after surgery, hence, excluded from the study. Preoperative medical comorbidities were not individually evaluated; therefore, their correlation with poor outcomes could not be judged. Premature discharge rate from the SICU was high due to fewer beds leading to more readmissions. There is no provision of a step down unit in our department for monitoring low-risk patients, leading to a large number of unwarranted admissions.

\section{Meaning of this study and implications for clinicians} Identification of perioperative risk factors affecting patient prognosis assists in preoperative optimization and postoperative intensive care, thus improving survival. Limiting the number of needless SICU admissions by setting up intermediate care units for monitoring low-risk patients will help save resources to manage the more critical patients effectively. Studies determining the impact of intermediate care units are limited at present. Provisions of an intermediate care facility for low-risk patients and an audit for the same would facilitate better postoperative care and improve patient survival.

\section{Conclusion}

This audit evaluated a limited number of risk assessment tools used frequently in day-to-day practice, to confirm their importance in judging the severity of illness/injury. These models as well as demographic profile of the patients help in identifying high-risk patients who might require SICU admission postoperatively. The need for postoperative critical care is significantly higher in males, elderly population, abdominal and trauma surgeries, emergency surgeries, patients with poor preoperative risk stratification scores, preexisting medical illness, major intraoperative blood loss, hypotension requiring inotropic support, and intra- or immediate post-operative respiratory problems. Adverse outcomes were observed in such patients, readmitted patients and in those with a SICU stay of $>7$ days.

\section{Financial support and sponsorship}

This research did not receive any specific grants from funding agencies in the public, commercial, or not-for-profit sectors.

\section{Conflicts of interest}

There are no conflicts of interest.

\section{References}

1. Ellis BW, Sensky T. A clinician's guide to setting up audit. BMJ 1991;302:704-7.

2. Bhat SA, Shinde VS, Chaudhari LS. Audit of Intensive Care Unit admissions from the operating room. Indian J Anaesth 2006;50:193-200.

3. Swann D, Houston P, Goldberg J. Audit of Intensive Care Unit admissions from the operating room. Can J Anaesth 1993;40:137-41.

4. Rose DK, Byrick RJ, Cohen MM, Caskennette GM. Planned and unplanned postoperative admissions to critical care for mechanical ventilation. Can J Anaesth 1996;43:333-40.

5. Sobol JB, Wunsch H. Triage of high-risk surgical patients for intensive care. Crit Care 2011;15:217.

6. Haller G, Myles PS, Wolfe R, Weeks AM, Stoelwinder J, McNeil J, et al. Validity of unplanned admission to an Intensive Care Unit as a measure of patient safety in surgical patients. Anesthesiology 2005;103:1121-9.

7. da Silva PS, de Aguiar VE, Fonseca MC. Risk factors and outcomes of unplanned PICU postoperative admissions: A nested case-control study. Pediatr Crit Care Med 2013;14:420-8.

8. Ejiro BA, Edomwonyi NP. Audit of Intensive Care Unit (ICU) admissions from the operating room: Experience at the University of Benin Teaching Hospital, Benin City, Nigeria. J Med Biomed Res 2012;11:9-17.

9. Cullen DJ, Nemeskal AR, Cooper JB, Zaslavsky A, Dwyer MJ. Effect of pulse oximetry, age, and ASA physical status on the frequency of patients admitted unexpectedly to a postoperative intensive care unit and the severity of their anesthesia-related complications. Anesth Analg 1992;74:181-8.

10. Phyu Phyu T, Kulkarni AH, Lim KH. Unplanned post-operative Intensive Care Unit admissions. Brunei Int Med J 2013;9:302-6.

11. Pearse RM, Harrison DA, James P, Watson D, Hinds C, Rhodes A, et al. Identification and characterisation of the high-risk surgical population in the United Kingdom. Crit Care 2006;10:R81.

12. Pedersen T, Eliasen K, Henriksen E. A prospective study of mortality associated with anaesthesia and surgery: Risk indicators of mortality in hospital. Acta Anaesthesiol Scand 1990;34:176-82.

13. Abelha F, Maia P, Landeiro N, Neves A, Barros H. Determinants of outcome in patients admitted to a Surgical Intensive Care Unit. Arq Med 2007;21:135-43.

14. Lupei MI, Chipman JG, Beilman GJ, Oancea SC, Konia MR. The association between ASA status and other risk stratification models on postoperative Intensive Care Unit outcomes. Anesth Analg 2014;118:989-94.

15. Lee TH, Marcantonio ER, Mangione CM, Thomas EJ, Polanczyk CA, Cook EF, et al. Derivation and prospective validation of a simple index for prediction of cardiac risk of major noncardiac surgery. Circulation 1999;100:1043-9.

16. Chalya PL, Gilyoma JM, Dass RM, Mchembe MD, Matasha M, Mabula JB, et al. Trauma admissions to the Intensive Care Unit at a reference hospital in Northwestern Tanzania. Scand J Trauma Resusc Emerg Med 2011;19:61.

17. Duncan PG, Cohen MM. Postoperative complications: Factors of significance to anaesthetic practice. Can J Anaesth 1987;34:2-8.

18. Bellomo R, Goldsmith D, Russell S, Uchino S. Postoperative serious adverse events in a teaching hospital: A prospective study. Med J Aust 2002;176:216-8.

19. Kaben A, Corrêa F, Reinhart K, Settmacher U, Gummert J, Kalff R, et al. Readmission to a Surgical Intensive Care Unit: Incidence, outcome and risk factors. Crit Care 2008;12:R123. 